\title{
Effect of preoperative incentive spirometry on fentanyl-induced cough: a prospective, randomized, controlled study
}

\author{
Vipin Kumar Goyal, Suresh Kumar Bhargava, and Birbal Baj \\ Department of Anesthesiology, Mahatma Gandhi Medical College, Jaipur, India
}

Background: Fentanyl-induced cough (FIC) has a reported incidence of $13-65 \%$ on induction of anesthesia. Incentive spirometry (IS) creates forceful inspiration, while stretching pulmonary receptors. We postulated that spirometry just before the fentanyl (F) bolus would decrease the incidence and severity of FIC.

Methods: This study enrolled 200 patients aged 18-60 years and with American Society of Anesthesiologists status I or II. The patients were allocated to two groups of 100 patients each depending on whether they received preoperative incentive spirometry before fentanyl administration. Patients in the F+IS group performed incentive spirometry 10 times just before an intravenous bolus of $3 \mu \mathrm{g} / \mathrm{kg}$ fentanyl in the operating room. The onset time and number of coughs after fentanyl injection were recorded as primary outcomes. Any significant changes in blood pressure, heart rate, or adverse effects of the drug were recorded as secondary outcomes.

Results: Patients in the F+IS group had a significantly lower incidence of FIC than in the F group (6\% vs. 26\%) $(\mathrm{P}<0.05)$. The severity of cough in the F+IS group was also significantly lower than that in group F (mild, 5 vs. 17; moderate 1 vs. 7; severe, 0 vs. 2) $(\mathrm{P}<0.05)$. The median onset time was comparable in both groups ( $9 \mathrm{~s}$ [range: 6-12 s] in both groups). Conclusions: Preoperative incentive spirometry significantly reduces the incidence and severity of FIC when performed just before fentanyl administration.

Key Words: Cough, Fentanyl, Incentive spirometry, Preoperative.

Corresponding author: Vipin Kumar Goyal, M.D.

Department of Anesthesiology, Mahatma Gandhi Medical College, Sitapura Institutional Area, Jaipur (Rajasthan) 302022, India

Tel: 91-8290342890, Fax: 91-01412770303

Email: dr.vipin28@gmail.com

ORCID: https://orcid.org/0000-0002-3318-3726

Received: January 18, 2017.

Revised: February 14, 2017 (1st); February 25, 2017 (2nd).

Accepted: February 28, 2017.

Korean J Anesthesiol 2017 October 70(5): 550-554

https://doi.org/10.4097/kjae.2017.70.5.550

\section{Introduction}

Opioids have long been an essential part of anesthesia practice, as both analgesics and premedication. The advantages of opioids include perioperative analgesia, attenuation of the hemodynamic response to laryngoscopy and intubation, and a reduction in the requirement of inhalational agents during general anesthesia. Short-acting opioids like alfentanil, fentanyl, and sufentanil are always preferred as intravenous (IV) boluses, which have faster onset and recovery and high potency, as well as a few side effects (e.g., chest wall rigidity, postoperative nausea and vomiting, respiratory depression, and sedation). On IV administration, fentanyl causes a cough in $13-65 \%$ of patients

(c) This is an open-access article distributed under the terms of the Creative Commons Attribution Non-Commercial License (http://creativecommons.org/ licenses/by-nc/4.0/), which permits unrestricted non-commercial use, distribution, and reproduction in any medium, provided the original work is properly cited. 
depending on the dose, concentration, rate of injection, route of administration, gender, and ethnicity [1-5]. The severity of FIC varies from a mild self-limiting episode to a severe spasmodic life-threatening cough. Adverse consequences are more dangerous in certain populations, such as patients undergoing ophthalmic or neurosurgical procedures [6-10].

There are numerous approaches to preventing FIC, including pharmacological and non-pharmacological methods, like low-dose propofol (10 mg) [11], IV pheniramine [12], dexmedetomidine-midazolam [13], IV lignocaine [14-16], tramadol [17], butorphanol [18], the huffing maneuver [19], acupressure, and drug dilution [1]. The incidence of FIC is lower in lighter smokers and older patients, while the presence of asthma and chronic obstructive pulmonary disease show no association with FIC incidence [3]. Preoperative incentive spirometry has a role in anesthesia practice, improving pulmonary function in patients with chronic obstructive and restrictive lung diseases and preventing postoperative atelectasis. Increased excitability of rapidly adapting receptors, also known as J receptors, located in the alveolar walls is important in the etiology of FIC. Incentive spirometry involves voluntary, slow, deep, and sustained inhalation and exhalation of air through a spirometer, which helps to recruit alveoli, increase lung expansion, strengthen the cough reflex, and clear the airway [20,21].

We hypothesized that preoperative incentive spirometry before giving fentanyl would reduce the incidence of FIC via its effect on lung physiology, along with the secondary benefit of preventing postoperative pulmonary complications.

In this prospective randomized study, we studied the effect of preoperative incentive spirometry before a fentanyl bolus on the onset time and severity of FIC (primary outcome), and on changes in blood pressure (BP), heart rate (HR), electrocardiogram (ECG) readings, and adverse effects of fentanyl (secondary outcomes).

\section{Materials and Methods}

This prospective, randomized, controlled study was conducted in the Department of Anesthesia of our institution following approval from the institutional ethics committee (MGHCH/ IEC/JPR/2014/211). Written informed consent was obtained from all patients. This study included 200 patients of both sexes, aged between 18 and 60 years, with American Society of Anesthesiologists (ASA) physical status I or II and undergoing elective surgery under general anesthesia. All patients underwent a thorough pre-anesthetic examination and routine laboratory tests, including a hemogram, coagulogram, biochemical indices, chest X-ray, and ECG; other investigations were performed as necessary. Patients were excluded from the study if they had a history of recent upper respiratory tract infection, asthma or chronic obstructive pulmonary disease, were on a bronchodilator or steroid therapy, were smokers, were on angiotensinconverting enzyme inhibitors, had a history of drug or opioid abuse, or had known hypersensitivity to fentanyl.

The sample size was estimated based on a reported incidence of cough of $32 \%$ after an IV bolus of fentanyl, assuming that incentive spirometry would result in a $20 \%$ reduction in the incidence of coughing. With $\alpha=0.05$ and $\beta=0.20,100$ patients were required in each group. Patients were randomly allocated to two groups: group F (fentanyl only) and group F+IS (fentanyl plus Incentive spirometry).

All patients were given oral alprazolam $0.25 \mathrm{mg}$ and pantoprazole $40 \mathrm{mg}$ as premedication, both the night before and in the morning $2 \mathrm{~h}$ before surgery. Upon arrival in the operating theater, IV access was secured and vital sign monitoring was started. Patients in group F+IS were instructed to perform incentive spirometry, which was done 10 times with an inspiratory interval of 3 seconds. The patients were required to lift the two balls in the spirometer (Romsons Medicons, Agra, India) until achieving an inspired volume of $900 \mathrm{ml}$ for 1 second. A $3 \mu \mathrm{g} /$ $\mathrm{kg}$ IV fentanyl bolus was given over a period of 2 seconds and flushed with an IV infusion of crystalloid. The fentanyl bolus was not preceded by any other IV medication. The response to the fentanyl bolus was recorded by a resident not participating in the study. The onset time and number of coughs after the fentanyl bolus were recorded for 1 minute as the primary outcome. Any episode of cough within 1 minute of fentanyl administration was classified as FIC. The severity of FIC was graded depending on the number of coughs, as follows: mild $=1-2$, moderate $=3-4$, and severe $\geq 5$. Any changes in BP, HR, ECG, or chest rigidity were recorded as secondary outcomes (just after, and 1, 3, and 5 min after the fentanyl bolus). Anesthesia was induced with propofol $2 \mathrm{mg} / \mathrm{kg}$ and the trachea was intubated with an appropriately sized endotracheal tube 4 minutes after a $0.5 \mathrm{mg} / \mathrm{kg}$ IV bolus of atracurium. Anesthesia was maintained with isoflurane in oxygen and nitrous oxide (40:60), with intermittent boluses of atracurium.

\section{Statistical analysis}

The patient characteristics (age, ASA status, and gender) were analyzed with the $t$-test for continuous variables and Pearson's chi-square test for categorical variables. The incidence and severity of FIC were compared using Fisher's exact test and the Mann-Whitney $U$ test, respectively. Two-way analysis of variance was used to assess changes in HR and BP before and after fentanyl injection in both groups. SPSS software (ver. 20.0; IBM Corp., Armonk, NY, USA) was used for the statistical analyses. A P value $<0.05$ was considered statistically significant. 


\section{Results}

The study evaluated 221 patients at the time of preoperative check-up, from December 2014 to September 2016. Twentyone patients were excluded based on the exclusion criteria. The remaining 200 patients were enrolled and randomized into two groups of 100 patients each (Fig. 1).

The patient demographics (age, sex and ASA status) were comparable in both groups (Table 1). The F+IS group had a markedly reduced incidence of FIC compared with the fentanyl only group (6\% vs. $26 \%$ ). The difference was significant $(\mathrm{P}<0.001)$. Cough severity was also lower in group $\mathrm{F}+\mathrm{IS}$ than in group $\mathrm{F}$ (mild, 5 vs. 17 ; moderate, 7 vs. 1 ; severe 0 vs. $2, \mathrm{P}<$ $0.001)$. The median time to onset of cough was comparable in both groups ( 9 s [range: 6-12 s]) (Table 2). The onset of FIC was within 15 seconds in all patients. No significant change in BP or HR before and after the fentanyl bolus was noted in either group. ECG change and chest wall rigidity were not observed after the fentanyl bolus in any patient.

\section{Discussion}

FIC is usually benign, but sometimes leads to an undesirable, exaggerated response like bronchospasm, aspiration of gastric contents, difficult ventilation, increased intracranial, intraocular, or intraabdominal pressure, or an increased incidence of postoperative nausea and vomiting [6-10]. These unwanted adverse effects are very undesirable at induction of anesthesia, preventing smooth and rapid patient recovery without postoperative adverse sequelae.

Although the mechanism underlying FIC is not well-established, possible explanations include inhibition of the central sympathetic system leading to vagal predominance, a pulmonary chemoreflex mediated by J receptors, reflex bronchocon-

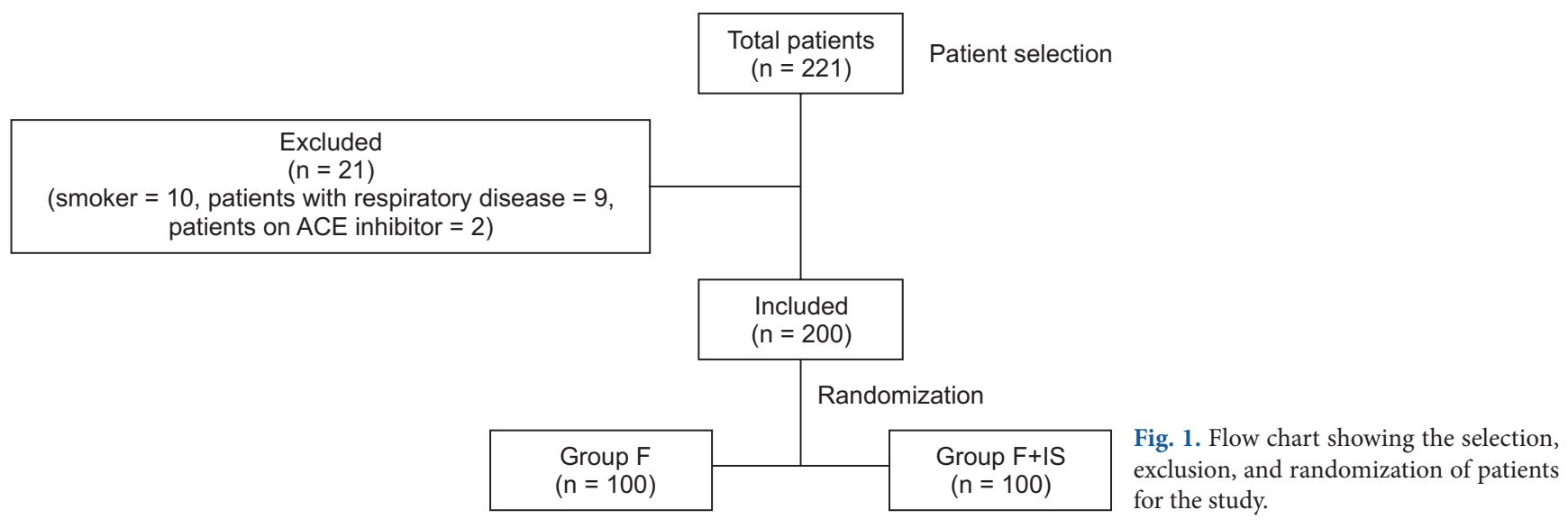

Table 1. Patient Demographics

\begin{tabular}{lccc}
\hline & Group F & Group F+IS & P value \\
\hline Age $(\mathrm{yr})$ & $39.05 \pm 12.05$ & $37.26 \pm 11.55$ & 0.887 \\
Sex (M/F) & $56 / 44$ & $49 / 51$ & 0.322 \\
ASA Status (I/II) & $64 / 36$ & $68 / 32$ & 0.550 \\
\hline
\end{tabular}

Data are presented as means \pm SD or as number of patients. ASA: American Society of Anesthesiologists physical status.

Table 2. Incidence, Severity and Time of Onset of Fentanyl-induced Cough

\begin{tabular}{lccc}
\hline & Group F & Group F+IS & P value \\
\hline Incidence of cough (\%) & 26 & 6 & $<0.001$ \\
Severity of cough & & & $<0.001$ \\
$\quad$ Mild & 17 & 1 & 0 \\
$\quad$ Moderate & 2 & $9(7-12)$ & \\
Severe & $9(6-11)$ & & \\
Time of cough onset (s) & & & \\
\hline
\end{tabular}

Data are presented as number of patients or median (IQR). 
striction after stimulation of tracheobronchial tree receptors, and histamine release [22-27]. A pulmonary chemoreflex mediated by J receptors located in the alveolar wall is thought to underlie the phenomenon of cough. Fentanyl may also elicit cough by stimulating irritant receptors in tracheal smooth muscles. Fentanyl enhances the excitability of rapidly adapting receptors to cause cough, and enhanced histamine release in the airways might be related to fentanyl induced increased cough sensitivity.

In this study, the observed incidence of FIC (26\%) was similar to previously reported rates (13-64\%). Solanki et al. [1] reported a lower incidence of FIC (12.7\%) in female cancer patients and postulated that this was due to the higher capsaicin sensitivity of women. Lin et al. [3] observed a higher incidence of FIC (65\%) after an IV bolus of fentanyl. The incidence of FIC may depend on the dose, concentration, route and rate of injection, as well as on gender, ethnicity, and pharmacological and non-pharmacological measures preceding fentanyl administration.

Preoperative incentive spirometry is routinely used to prevent and treat postoperative pulmonary complications in patients with respiratory compromise (obstructive or restrictive lung disease). In patients undergoing major upper abdominal and thoracic surgery, incentive spirometry is used in the intensive care unit. Basal atelectasis, pneumonia, and respiratory failure (type I and II) are common postoperative complications, with reported incidence rates of $2-39 \%$ [28]. Incentive spirometry mimics natural sighing or yawning and encourages the patient to take a long, slow, deep breath. The recruitment of alveoli and improved gas exchange ultimately reduces the risk and severity of pulmonary complications. In a study of patients undergoing laparoscopic cholecystectomy, Kundra et al. [20] observed that lung functions were better preserved in patients performing preoperative incentive spirometry. Bergin et al. [21] also reported better postoperative pulmonary outcomes after preoperative incentive spirometry in patients undergoing knee and hip joint replacement. In a non-randomized pilot study of 263 patients, Westwood et al. [29] found that addition of incentive spirometry to an intensive postoperative physiotherapy program decreased the occurrence of pulmonary complications ( $6 \%$ vs. $17 \%, \mathrm{P}=$ 0.01 ) and length of stay in the surgical high-dependency unit (3.1 vs. 4 days, $\mathrm{P}=0.03$ ). Although the American Association of Respiratory Care guidelines of 2011 stated that incentive spirometry alone is not recommended for routine use in the pre- and postoperative setting to prevent postoperative pulmonary complications, it is still used widely in anesthesia practice [30]. Incentive spirometry leads to preconditioning of the lungs for FIC via maximal expansion of small airways and alveoli, attenuating the pulmonary stretch reflex, which is a factor in FIC. Ambesh et al. [19] reported that incentive spirometry had a similar effect on pulmonary mechanics as the huffing maneuver.

One limitation of our study was that we administered oral alprazolam $2 \mathrm{~h}$ before surgery as a routine institutional practice, although preoperative anxiolytic like oral alprazolam given the morning before surgery may falsely decrease the incidence of FIC.

In conclusion, both the incidence and severity of FIC can be effectively attenuated by preoperative incentive spirometry, which has the additional benefit on preoperative pulmonary optimization of patients.

\section{References}

1. Solanki SL, Doctor JR, Kapila SJ, Gehdoo RP, Divatia JV. Acupressure versus dilution of fentanyl to reduce incidence of fentanyl-induced cough in female cancer patients: a prospective randomized controlled study. Korean J Anesthesiol 2016; 69: 234-8.

2. Böhrer H, Fleischer F, Werning P. Tussive effect of a fentanyl bolus administered through a central venous catheter. Anaesthesia 1990; 45: 18-21.

3. Lin JA, Yeh CC, Lee MS, Wu CT, Lin SL, Wong CS. Prolonged injection time and light smoking decrease the incidence of fentanyl-induced cough. Anesth Analg 2005; 101: 670-4.

4. Yu H, Yang XY, Zhang X, Li Q, Zhu T, Wang Y, et al. The effect of dilution and prolonged injection time on fentanyl-induced coughing. Anaesthesia 2007; 62: 919-22.

5. Dicpinigaitis PV, Rauf K. The influence of gender on cough reflex sensitivity. Chest 1998; 113: 1319-21.

6. Phua WT, Teh BT, Jong W, Lee TL, Tweed WA. Tussive effect of a fentanyl bolus. Can J Anaesth 1991; 38: 330-4.

7. Tweed WA, Dakin D. Explosive coughing after bolus fentanyl injection. Anesth Analg 2001; 92: 1442-3.

8. Lim KJ, Lee SK, Lee HM, Park EY, Kim MH, Kim YS, et al. Aspiration pneumonia caused by fentanyl-induced cough -a case report-. Korean J Anesthesiol 2013; 65: 251-3.

9. Li CC, Chen SS, Huang CH, Chien KL, Yang HJ, Fan SZ, et al. Fentanyl-induced cough is a risk factor for postoperative nausea and vomiting. Br J Anaesth 2015; 115: 444-8.

10. Bennett JA, Abrams JT, Van Riper DF, Horrow JC. Difficult or impossible ventilation after sufentanil-induced anesthesia is caused primarily by vocal cord closure. Anesthesiology 1997; 87: 1070-4. 
11. Firouzian A, Emadi SA, Baradari AG, Mousavi R, Kiasari AZ. Can low dose of propofol effectively suppress fentanyl-induced cough during induction of anaesthesia? A double blind randomized controlled trial. J Anaesthesiol Clin Pharmacol 2015; 31: 522-5.

12. Arslan Z, Çalık ES, Kaplan B, Ahiskalioglu EO. The effect of pheniramine on fentanyl-induced cough: a randomized, double blinded, placebo controlled clinical study. Rev Bras Anestesiol 2016; 66: 383-7.

13. Yu J, Lu Y, Dong C, Zhu H, Xu R. Premedication with intravenous dexmedetomidine-midazolam suppresses fentanyl-induced cough. Ir J Med Sci 2012; 181: 517-20.

14. Lin CS, Sun WZ, Chan WH, Lin CJ, Yeh HM, Mok MS. Intravenous lidocaine and ephedrine, but not propofol, suppress fentanyl-induced cough. Can J Anaesth 2004; 51: 654-9.

15. Pandey CK, Raza M, Ranjan R, Singhal V, Kumar M, Lakra A, et al. Intravenous lidocaine $0.5 \mathrm{mg} \cdot \mathrm{kg}^{-1}$ effectively suppresses fentanylinduced cough. Can J Anaesth 2005; 52: 172-5.

16. Pandey CK, Raza M, Ranjan R, Lakra A, Agarwal A, Singh U, et al. Intravenous lidocaine suppresses fentanyl-induced coughing: a doubleblind, prospective, randomized placebo-controlled study. Anesth Analg 2004; 99: 1696-8.

17. Elmawgoud AA. Effect of tramadol on fentanyl induced cough: a double-blind, randomized, controlled study. Egyptian J Anaesth 2013; 29: 301-4.

18. Cheng XY, Lun XQ, Li HB, Zhang ZJ. Butorphanol suppresses fentanyl-induced cough during general anesthesia induction: A randomized, double-blinded, placebo-controlled clinical trial. Medicine (Baltimore) 2016; 95: e3911.

19. Ambesh SP, Singh N, Gupta D, Singh PK, Singh U. A huffing manoeuvre, immediately before induction of anaesthesia, prevents fentanylinduced coughing: a prospective, randomized, and controlled study. Br J Anaesth 2010; 104: 40-3.

20. Kundra P, Vitheeswaran M, Nagappa M, Sistla S. Effect of preoperative and postoperative incentive spirometry on lung functions after laparoscopic cholecystectomy. Surg Laparosc Endosc Percutan Tech 2010; 20: 170-2.

21. Bergin C, Speroni KG, Travis T, Bergin J, Sheridan MJ, Kelly K, et al. Effect of preoperative incentive spirometry patient education on patient outcomes in the knee and hip joint replacement population. J Perianesth Nurs 2014; 29: 20-7.

22. El Baissari MC, Taha SK, Siddik-Sayyid SM. Fentanyl-induced cough--pathophysiology and prevention. Middle East J Anaesthesiol 2014; 22: 449-56.

23. Paintal AS. Mechanism of stimulation of type J pulmonary receptors. J Physiol 1969; 203: 511-32.

24. Sant'Ambrogio FB, Sant'Ambrogio G. Circulatory accessibility of nervous receptors localized in the tracheobronchial tree. Respir Physiol 1982; 49: 49-73.

25. Yasuda I, Hirano T, Yusa T, Satoh M. Tracheal constriction by morphine and by fentanyl in man. Anesthesiology 1978; 49: 117-9.

26. Kamei J, Nakanishi Y, Asato M, Ikeda H. Fentanyl enhances the excitability of rapidly adapting receptors to cause cough via the enhancement of histamine release in the airways. Cough 2013; 9: 3.

27. Rosow CE, Moss J, Philbin DM, Savarese JJ. Histamine release during morphine and fentanyl anesthesia. Anesthesiology 1982; 56: 93-6.

28. Fisher BW, Majumdar SR, McAlister FA. Predicting pulmonary complications after nonthoracic surgery: a systematic review of blinded studies. Am J Med 2002; 112: 219-25.

29. Westwood K, Griffin M, Roberts K, Williams M, Yoong K, Digger T. Incentive spirometry decreases respiratory complications following major abdominal surgery. Surgeon 2007; 5: 339-42.

30. Restrepo RD, Wettstein R, Wittnebel L, Tracy M. Incentive spirometry: 2011. Respir Care 2011; 56: 1600-4. 